\title{
From the periphery to the centre: Securing the place at the heart of the TESOL field for First Nations learners of English as an Additional Language/Dialect
}

\author{
Denise Angelo and Catherine Hudson \\ School of Literature, Languages E Linguistics, \\ Australian National University, Canberra, Australia
}

Abstract: Indigenous learners of English as an Additional Language or Dialect $(E A L / D)$ have historically not been the central focus of TESOL expertise here in Australia, or overseas. Despite moves towards inclusion increasing over the last two decades, there is an ongoing tendency for Indigenous EAL/D learners to remain on the periphery of current TESOL advocacy, research and practices in Australia. They are still often overlooked, as identification processes and support settings for migrant and refugee services are mismatched to Indigenous $E A L / D$ learning contexts. Indigenous $E A L / D$ learners, especially with un-/under-recognised contact languages (creoles and related varieties), can remain invisible in classrooms with mainstream curriculum and assessment practices (Angelo, 2013; Angelo $\mathcal{E}$ Hudson, 2018; Gawne et al., 2016; Macqueen et al., 2019). Hence, we argue that understanding and consideration of Indigenous EAL/D learners' needs should become a priority in TESOL initiatives. This paper aims to place Indigenous $E A L / D$ learners at the centre by alerting the TESOL field to a recent body of research and development on new Indigenous contact languages and whole class EAL/D teaching and assessment practices. Clarifying substantial issues and providing solutions, the paper makes Indigenous $E A L / D$ its central focus, highlighting areas that otherwise result in "forgettings" about needs particular to Indigenous EAL/D learners. Thus informed, the Australian TESOL profession will surely include First Nations EAL/D learners at the heart of future discourse and initiatives.

Key words: TESOL field, First Nations/Indigenous learners, EAL/D, EFL, ESL, ESD, ELL, mainstream classroom teachers, contact language ecologies, language awareness, CLIL, language proficiency assessment 


\section{Introduction}

In Australia, the understanding that some Indigenous ${ }^{i}$ students are English as an Additional Language or Dialect $(\mathrm{EAL} / \mathrm{D})^{\mathrm{ii}}$ learners has been slowly growing, if somewhat inconsistently. The social justice mindset of the Australian TESOL community has ensured that Indigenous EAL/D learners are nowadays more regularly acknowledged as members of the full EAL/D learner population, along with the other EAL/D cohorts with overseas language backgrounds historically most commonly serviced by TESOL professionals. However, in practice, there is much to be done to achieve consistent and full inclusion of Indigenous EAL/D learners by the TESOL profession in Australia.

Indigenous EAL/D learners have stood on the margins of the TESOL field partly because, unlike migrant and refugee background learners, with one exception, they have not received dedicated resourcing as EAL/D learners through Commonwealth funding, and have thus lacked TESOL-oriented services. The funding exception was the English as a Second LanguageIndigenous Language Speaking Students (ESL-ILSS) program (1998-2009), although the funding conditions differed significantly from programs for overseas background EAL/D learners: ESLILSS was limited to students' first year of schooling only and eligibility extended to Indigenous students who spoke a traditional language or a creole as their first language (L1) and were prebeginner proficiency in Speaking. Post-program, the targeted proficiency was a beginner level in Speaking (DEST, 2004 p. 35), insufficient for accessing the mainstream curriculum through mainstream pedagogy (see Angelo \& Hudson, 2018 for example mainstream assessment interactions).

Pivotally related to this historic lack of dedicated funding, the Indigenous EAL/D cohort has been on the TESOL periphery because they have had little access to TESOL expertise and advocacy. Indigenous EAL/D learners were, and still are, taught by mainstream teachers with generalist training, through the mainstream curriculum, in mainstream school programs (i.e. never intensive centres) although a small number of bilingual programs have been implemented for over four decades (see Devlin et al., 2017 for the Northern Territory). This mainstream context stands, independently of whether the learners come into school with beginner levels of English proficiency and are in English as a Foreign Language (EFL) contexts with little access to Standard Australian English (SAE) in the environment (DET 
(Qld), 2020; Hudson \& Angelo, 2014; Poetsch this volume). The unfunded EAL/D status has meant that the Indigenous EAL/D cohort has stood on the edges of the political life of the TESOL field, with their belated admission into the EAL/D population in TESOL policy gaining momentum around two decades ago, and nationwide acknowledgement achieved a decade ago in the Australian Curriculum Assessment and Reporting Authority (ACARA) EAL/D Resources (ACARA, 2011/2014, 2015).

It is regrettable that there has been and is still now substantial insecurity about funding of targeted EAL/D programs in the migrant/refugee sector (see Oliver et al., 2017). However, dedicated EAL/D funding has provided a basis for communities of TESOL practice to develop. Funded TESOL specialist teachers share key conceptualisations about second language acquisition and development, e.g. BICS-CALP (Cummins, 1984) and second language teaching and assessment frameworks. They have also developed processes for servicing migrants and refugees in intensive centres and mainstream schools. ACTA (Australian Council of TESOL Associations), the peak representative body for the TESOL profession, has undertaken advocacy and nurtured communities of practice through professional development and biennial conferences. Arguably, for the most part, these activities have revolved around the funded EAL/D cohort receiving TESOL professional services rather than around Indigenous EAL/D learners and their generalist trained teachers. In sum, largely as a washback effect from funding policies, the TESOL profession in Australian schools has historically centred on students of overseas backgrounds.

\subsection{The nature of "forgettings"}

This central focus of the Australian TESOL profession predominantly on students with overseas backgrounds gives rise to numerous knock-on effects. The field of research on EAL/D proficiency assessment has, for instance, a dominant focus on students with overseas backgrounds. The vast majority of the experienced TESOL practitioner workforce has worked with migrant and refugee cohorts because of funded programs (Oliver et al., 2017). Populations of overseas background EAL/D learners generally occur in different areas to Indigenous background EAL/D learners (complementary distribution), so more in urban areas, in southern states/regions etc versus more in remote areas, in northern states/regions etc. This factor also constrains the 
presence of TESOL workforces and the research involving them and their students. Hence, quality research on second language proficiency assessment, for example, if drawing on (employed) EAL/D teaching professionals or their (funded) EAL/D learners as participants, does not confront the very different identification and assessment contexts of Indigenous EAL/D learners (e.g. Creagh, 2014; Davison \& Michell, 2014).

Indeed, a dominant focus on overseas language background EAL/D learners can lead to Indigenous students being omitted from the historical record of language proficiency research, just because they are not always kept in mind. A case in point is the use of the NSW trial of the reliability and validity of the ACARA EAL/D Progressions (CESE, 2015) in subsequent advocacy. The trial itself offers copious alerts on the need for further research "in particular Aboriginal students" (CESE, 2015 p. VII) (see also CESE, 2013, p. 7; 2015, pp. 16, 54, 63, 67); the other Indigenous cultural grouping, Torres Strait Islander students, are not mentioned. Still, as far as it goes, this is a responsible recommendation on a number of grounds: The sample size of Aboriginal students was small; most teachers were unsure about the applicability of the progressions for Aboriginal students; only 4 teachers assessed Aboriginal students; work from just 18 Aboriginal students was double marked; Aboriginal students seem to have been included on the grounds of ethnicity rather than EAL/D status etc (CESE, 2015). Nevertheless, this significant qualification about Indigenous EAL/D assessment contexts has since fallen away in some generalised advocacy claims (e.g. ACTA, 2019 , p. 7). In this manner, Indigenous students' language learning and proficiency assessment contexts are minoritised, a further washback effect from a TESOL focus placed elsewhere.

The forgetting of Indigenous EAL/D learning contexts can be quite pronounced even in some current Australian TESOL materials. For example, ACARA's new EAL/D infographic promotes the diversity of EAL/D learners with indications of their individual learning characteristics, previous education and life experiences. Tellingly, there is no explicit reference to a recognisable Indigenous EAL/D learner context or experience. Just another 'forgetting' perhaps? Figure 1 below illustrates how Indigenous EAL/D learners were not mindfully kept as a central focus in the ACARA material: On the left is the ACARA infographic box depicting "diverse" EAL/D learners, but lacking clear Indigenous representation; on the right, by way of contrast, 
we have added our own speech bubble annotations, exemplifying some salient features of diversity amongst Indigenous EAL/D learners and their learning contexts. Such omissions from national education materials do nothing to reinforce the just but historically very recent policy move to finally and definitively allow Indigenous children to take their places in the EAL/D population if they are EAL/D learners. In fact, it fosters their existing invisibility and the confusion amongst teachers who, research shows, may still be unsure whether students with Indigenous backgrounds can also be EAL/D learners (e.g. DET (Qld), 2020, p. 12; Dixon \& Angelo, 2014; Sellwood \& Angelo, 2013).

Figure 1: ACARA EAL/D learner infographic with added Indigenous context examples


I speak Kriol like everybody in my community and some Mangarrayi, the language for this place, and some Alawa from my dad's side.

The Torres Strait Islander students all talk Yumplatok. The Aboriginal students talk like where their family comes from. The Hmong and Nepali and African students can do that too.

My family and I speak a bit of English if we go into town. The teacher speaks it at school and my class and I try to speak it with her.

In my school we learn to read and write in our own language first. As we learn a bit more English we can do it in English too.

Note. Excerpt (C) ACARA (n.d.) English as an Additional Language or Dialect Infographic (box on left), with authors' additions of blue speech bubbles (on right) (https://www.australiancurriculum.edu.au/resources/student-diversity/meetingthe-needs-of-students-for-whom-english-is-an-additional-language-or-dialect/)

In a similar vein, while more and more TESOL-informed documents include "Indigenous" (or "Aboriginal" and "Torres Strait Islander") students as potential EAL/D learners, often indeed entered first in the list respecting First Nations status, they are entered as a monolithic ethnicity-based grouping, without differentiation, in stark contrast with the detailed categories of EAL/D learners involving overseas backgrounds or connections (see Figure 2 below). The overseas differentiations primarily 
reflect funding program settings, with each visa class, at some time, equating to a level of funding or TESOL service. This is not to trivialise these categories: For TESOL specialists they may be suggestive of important educational needs, such as potential disrupted schooling in the case of refugee backgrounds. However, the heterogeneity of Indigenous EAL/D learner groups and their differing language ecologies also imply significantly diverse educational needs, as we shall see. Australia's TESOL profession has a history of advocating for the recognition of specific EAL/D learner sub-groups on the basis of their learning needs as a social justice stance, and will be able to take on Indigenous EAL/D subgroups too.

\section{Figure 2. ACARA Definition of EAL/D learners}

EAL/D students are those whose first language is a language or dialect other than English and who require additional support to develop proficiency in Standard Australian English (SAE).

These students may include:

- Aboriginal and Torres Strait Islander students

- immigrants to Australia and temporary visa holders from non-English speaking countries

- students with a refugee background

- children born in Australia of migrant heritage where English is not spoken at home

- English-speaking students returning to Australia after extended periods in non-English speaking settings

- children of deaf adults who use Auslan as their first language

- international students from non-English speaking countries.

Note. Definition of students for whom English is an additional language or dialect. From ACARA. n.d. (https://www.australiancurriculum.edu.au/resources/studentdiversity/meeting-the-needs-of-students-for-whom-english-is-an-additional-languageor-dialect/)

\subsection{Benefits of informed, inclusive TESOL field}

The point here is not to undervalue TESOL advocacy or such national achievements for EAL/D learners as the second language assessment tools in the 1990s (McKay et al., 1994; Australian Education Council (AEC), 1994) and the inclusive national EAL/D resources (e.g. ACARA, 2011/2014, 2015), but to look to 
the future of TESOL consultation, research, concept development, national EAL/D policy advocacy, initiatives and implementation in challenging times. The Indigenous EAL/D student cohort will benefit from inclusion in the greater TESOL work, as long as it is well-informed by in-depth engagement with the pertinent issues. Furthermore, the Indigenous EAL/D field has much to offer the Australian TESOL profession. For example, as a result of the funding and servicing constraints for Indigenous EAL/D learners outlined above, the mainstay of supporting EAL/D learners of Indigenous backgrounds of all proficiency levels has been via professional development. When jurisdictions recognise their Indigenous EAL/D learners, they provide or encourage upskilling of their generalist teachers so they can more effectively teach these, and indeed all, EAL/D learners, in whole class, mainstream curriculum contexts ${ }^{\text {iii. }}$ This professional development expertise could prove useful for TESOL professionals, especially where "mainstreaming" for overseas background EAL/D learners with earlier L2 proficiency levels is more commonplace, for example under changed service or funding provisions. Cross-fertilisation between Indigenous and overseas background EAL/D experiences will therefore promote more effective responses for mainstreamed $\mathrm{EAL} / \mathrm{D}$ cohorts. Just as it is possible to respond to the differences in context between refugee and migrant EAL/D learners, and hold them within single policy initiatives, so is it also possible to respond to Indigenous EAL/D learners, and their heterogeneity, within the same, single EAL/D policy field. There is strength for all behind such unity, a synergy to be gained by encompassing the full cohort of EAL/D learners.

\section{Centring the L1s of Indigenous EAL/D learners in the TESOL field}

Having discussed the nature of forgettings, the paper now draws the attention of the TESOL field to specific matters necessary for understanding the language and learning situations of Indigenous EAL/D learners and to illustrations of responses tailored for their language learning needs. In this manner, the broader TESOL field can be informed of recent research and be aware and supportive of approaches for Indigenous EAL/D learners. This work sometimes involves new concepts and practices, but sometimes it is a matter of recalling concepts that have faded from contemporary Australian TESOL thinking. In any case, all are compatible with core TESOL values and processes, such as 
supporting and drawing on the young learners' L1s, explicitly teaching language demands of tasks and utilising EAL/D proficiency assessment tools. Much work described here is Queensland based ${ }^{\mathrm{iv}}$, but this still serves to illustrate efforts in the area of Indigenous EAL/D for the attention of the TESOL field.

Research tells us that classroom teachers may not know that Indigenous students are EAL/D learners, even when they have low levels of proficiency in Standard Australian English. In the post-colonial Indigenous language landscape profoundly shaped by language contact, Indigenous students' L1s may lack standardised nomenclature and may not even be recognised as languages (e.g. Angelo et al., 2019). Clearly then, when focussing on Indigenous EAL/D learners, the multilingual advice usually given by TESOL professionals about valuing students' L1s, such as supporting the use of L1 in the classroom, using L1 in assessment, accepting translanguaging etc. must be greatly extended. Informed advice must include issues related to the contact language situations and their variable states of recognition. The capacity to give advice about the value of support for $\mathrm{L} 1$ is fundamental to the knowledge set of the contemporary TESOL specialist, and yet with this Indigenous $\mathrm{EAL} / \mathrm{D}$ cohort assumptions must be questioned, new knowledge acquired and framings altered for this L1 advice to be useful. Informed advice about L1 is a vital issue, but only one of other issues at hand. Including Indigenous EAL/D learners in a meaningful way, involves additional knowledge, namely the dynamics of language contact and shift in Australia since invasion over 200 years ago, and additional ways of working, namely including language awareness processes in EAL/D teaching toolkits.

This point is key. For TESOL advocacy and initiatives to include Indigenous EAL/D learners as a core cohort consistently at the heart of matters, truly and consistently moving beyond forgettings, requires considerable effort and engagement with the substance of their context as well as the ramifications. This means more than remembering to represent Indigenous EAL/D learners in infographics, to depict their diversity in lists or to include research caveats concerning them, although each is a step in the right direction. There are deep implications behind the fact that Indigenous EAL/D learners have been inconsistently recognised, or that many of their language communities have undergone or are undergoing language shift to an un-named or under-described contact language etc. Speaking for the full EAL/D cohort is a 
responsibility that requires an intentional decision to make Indigenous $\mathrm{EAL} / \mathrm{D}$ learners a central concern. This requires staying up to date with information and processes about Indigenous students' rich language ecologies and diverse English language contexts (i.e. EFL, ESL, as well as issues of distant dialects of English), managing classroom learning for EAL/D learners in mainstream curriculum contexts and locally sensitive EAL/D proficiency assessment. These areas are covered in the following sections.

\subsection{Recognising language backgrounds of Indigenous EAL/D learners}

Firstly, we outline research on post-colonial language ecologies. According to the 2020 National Indigenous Languages Report, twelve traditional Indigenous languages are being acquired by children as their L1 and everyday language of communication (DoITRDC et al., 2020). Most traditional language speakers are recognised by their community and at school because they are named and entirely separate from English. However, this does not automatically translate into commensurate $\mathrm{L} 1$ and EAL/D services.

Recognition of students who speak new Indigenous contact languages is more patchy. Kriol and Yumplatok/Torres Strait Creole have a few decades of official policy recognition (e.g. in Lo Bianco, 1987; HoRSCATSIA, 1992), so some communities and their schools are nowadays more likely to know these naming conventions and have a degree of awareness of these languages and speakers' EAL/D status. However, many speakers of new Indigenous contact languages have gone unrecognised, which means there is no data on them as L1 speakers of a language other than English to indicate students' likely EAL/D learner status (Angelo, 2013; Dixon \& Angelo, 2014).

"Aboriginal English(es)" is a source of complexity for the TESOL field to be aware of. This umbrella term is applied to a broad range of varieties standing loosely in a dialect relationship to Standard Australian English (Dickson, 2019; Eades, 2014; Malcolm, 2018). A Torres Strait English has also been described (Shnukal, 2001). There are many different kinds of Aboriginal English(es), and not all speakers of Aboriginal English(es) have EAL/D learning needs: some speak dialects very close to and mutually comprehensible with Standard Australian English (not EAL/D learners), some speak dialects very different from Standard Australian English (potential EAL/D learners). Generally, the 
reason why researchers treat all these different varieties together is to argue that all forms of Indigenised Englishes are valid, a position we should all support. However, this broad conceptualisation of Aboriginal English(es) does not map straightforwardly or automatically onto EAL/D needs. The range of varieties included by terms such as Aboriginal English or Aboriginal Englishes is so great, that much thought and discernment is required when considering whether a speaker of an Aboriginal English is or is not an EAL/D learner: Speakers of the varieties of Aboriginal English(es) which are very close to and mutually comprehensible with SAE are not. Just like speakers of other dialects of English such as from New Zealand or England will vouchsafe, they do not require $\mathrm{EAL} / \mathrm{D}$ services despite differences in their way of speaking (Angelo, in press b). This matter cannot be clarified by a student's language background alone, but by judicious consideration of their EAL/D proficiency levels.

In these rich and complex contemporary Indigenous language landscapes, then, schools often cannot straightforwardly identify young Indigenous students as EAL/D learners via standard questions on enrolment forms on school entry. As invisible EAL/D learners, their English language learning needs are unlikely to be met in mainstream curriculum, with teaching and assessment delivered by generalist trained teachers via the medium of Standard Australian English (Angelo \& Carter, 2015; Gawne et al., 2016; Hudson \& Angelo, 2020).

\subsection{New Indigenous contact language contexts}

Carter et al. (2020, p. 147) suggest that instances of omission of Indigenous EAL/D learners are in all likelihood attributable to a lack of awareness about contemporary Indigenous language ecologies. In fact, supporting this claim, it is only in 2020 that for the first time in an accessible public document, the National Indigenous Languages Report puts other less recognised new Indigenous contact languages in the picture, additional to the two widespread and well-recognised creoles, Kriol and Yumplatok (DoITRDC et al., 2020, p. 57). Yet it must be said that even Yumplatok, also called Torres Strait Creole or Broken, with a linguistic description (Shnukal, 1988) and a degree of long-term policy presence, only inconsistently garners educational responses, a pattern common for creole languages worldwide (Angelo, 2021). So even with this recognition, students with this 
background are not always recognised and assessed as EAL/D learners and responded to with EAL/D pedagogy (Angelo, 2012; Sellwood \& Angelo, 2013). Clearly there is a lot to understand and respond to regarding recognition of Indigenous EAL/D learners and their L1s.

In addition to Yumplatok and Kriol, there is a growing awareness of a mosaic of creoles and related varieties spoken by Aboriginal and Torres Strait Islander people across northern Australia which have much less official recognition. In the Northern Territory, new types of Indigenous contact languages have been described in the last two decades: the mixed languages of Light Warlpiri (O’Shannessy, 2005) and Gurindji Kriol (Meakins, 2013), and the blended languages of Wumpurrarni English (Disbray \& Simpson, 2004) and Alyawarr English (Dixon, 2018). In the jurisdiction of Queensland, too, awareness of new Indigenous languages has been growing. Here for example, the past decade has seen publications on:

- a grammatical description of an entire new Indigenous contact language, Lockhart River Creole (Mittag, 2016)

- language features of a new Indigenous contact language (e.g. Gourlay \& Mushin, 2015; Mushin \& Watts, 2016)

- sketches and typologies of new Indigenous contact languages, including Queensland (Angelo, in press a)

- sociolinguistic studies of new Indigenous contact languages (e.g. Munro \& Mushin, 2016; Mushin, et al., 2016)

- learning outcomes of students with a new Indigenous contact language background in classroom contexts of mainstream English curriculum and pedagogy (e.g. Angelo, 2012; Angelo \& Hudson, 2018; Fraser et al., 2018; Mushin et al., 2013)

- education differentiation for students who speak new Indigenous contact languages (Angelo \& Carter, 2015; Carter et al., 2020; McTaggart \& Curro, 2009)

- community-based descriptions and portrayals of new Indigenous contact languages (e.g. Angelo et al., 2019; Language Perspectives, 2009, the first of a suite of Community Vernacular Language Posters, see DET (Qld), 2020, p. 113 for list; Nancarrow, 2014, one example from a series of stories from Mornington Island)

- invisibility of new Indigenous contact languages in education, Census etc (e.g. Sellwood \& Angelo, 2013; Angelo \& McIntosh, 2014; Dixon \& Angelo, 2014)

- EAL/D identification and assessment and speakers of new 
Indigenous contact languages (e.g. Angelo, 2013; Hudson \& Angelo, 2014, 2020)

The majority of Indigenous EAL/D learners have as their L1s new Indigenous contact languages and, where these benefit from EAL/D interventions, Indigenised English dialects. This raises issues not experienced by most overseas background EAL/D learners and their teachers. The English related vocabulary can obscure major linguistic differences between them and Standard Australian English, especially as different morphosyntactic sub-systems are less analysable by generalist classroom teacher skillsets (Hudson \& Angelo, 2020; Sellwood \& Angelo, 2013). In addition, for speakers of Aboriginal English in Perth, Malcolm (2002) has also shown that differences in sociocultural language practices ("genres") are also not easily visible to non-Indigenous teachers.

In sum, the postcolonial language contexts of most Indigenous EAL/D learners is far from straight-forward, and their language learning needs are all too easily obscured by other agendas (Angelo, 2012; Carter et al., 2020; Dixon \& Angelo, 2014). If the TESOL field were abreast of such issues, theirs would be a useful voice. As the above taste of the research record shows, understandings of new Indigenous contact languages are constantly growing and being clarified, so staying informed requires conscious commitment.

\subsection{A framework for differentiating Indigenous EAL/D learners}

The most significant variables for Indigenous EAL/D learners arise from their different language contexts, as shown in Table 1 below. All "types" of Indigenous language can function as full languages and convey speakers' Indigenous identity. However, as an L1, each type gives rise to somewhat different EAL/D learning needs, depending on the absence or degree of any surface similarity with Standard Australian English (aka semantic transparency, lexical overlap). Recognition matters as postcolonial Indigenous language ecologies are dynamic (i.e. changing), often un-/under-recognised (i.e. L1s might not be named or valued) and un-/under-described (i.e. their linguistic structure and mutual comprehensibility, or otherwise, with Standard Australian English might not yet have been investigated with 
speakers). The local context of English language use varies significantly for Indigenous EAL/D learners. Unlike EAL/D learners with overseas backgrounds in Australia, some Indigenous students may technically learn English as a Foreign Language, because Standard Australian English is only used in the classroom and not otherwise spoken in other everyday interactions. Finally, some Indigenous EAL/D learners receive official L1 support through bilingual programs, but most Indigenous EAL/D learners are in whole class, mainstream curriculum contexts where perhaps teaching assistants or other students share their L1. Print-based materials are only available for some L1s.

\section{Table 1. Variables impacting on Indigenous EAL/D learner needs}

\begin{tabular}{|l|l|}
\hline $\begin{array}{l}\text { type of language spoken as L1 } \\
\text { - traditional Indigenous language } \\
\text { - new Indigenous contact language } \\
\text { - Indigenised English }\end{array}$ & $\begin{array}{l}\text { The linguistic 'distance' and 'separation' of students' L1 from } \\
\text { Standard Australian English requires different TESOL responses. New } \\
\text { Indigenous contact languages have some lexical overlap. Some } \\
\text { 'heavy' Indigenised Englishes are distant from Standard Australian } \\
\text { English and speakers benefit from EAL/D support but some are so } \\
\text { close that TESOL interventions for their speakers are unsuitable. }\end{array}$ \\
\hline $\begin{array}{l}\text { recognition trajectory of L1 } \\
\text { - community recognition }\end{array}$ & $\begin{array}{l}\text { Traditional Indigenous L1s are typically named and valued in their } \\
\text { speech community. New Indigenous contact languages such as } \\
\text { creoles, mixed languages and blended languages and Indigenised } \\
\text { Englishes might not be, and might mistakenly be believed to be one of } \\
\text { the source languages, such as English. }\end{array}$ \\
\hline $\begin{array}{l}\text { local use of Standard Australian } \\
\text { English }\end{array}$ & $\begin{array}{l}\text { When Standard Australian English is only used in class and an } \\
\text { Indigenous language, traditional or new, is used for all other everyday } \\
\text { communication, this is technically a foreign language learning (EFL) } \\
\text { setting and typical of remote communities, but also in tight networks } \\
\text { in regional town and urban settings. In areas where Indigenous EAL/D } \\
\text { learners use Standard Australian English in aspects of daily life apart } \\
\text { from school, this is described as an ESL context. }\end{array}$ \\
\hline $\begin{array}{l}\text { L1 support for classroom } \\
\text { learning and literacy }\end{array}$ & $\begin{array}{l}\text { In some remote Indigenous communities there has been a history of } \\
\text { bilingual (dual language) education, with initial classroom learning } \\
\text { and literacy in L1. Here L1 literacy in adults and L1 print resources } \\
\text { are more common. In other Indigenous language speaking contexts L1 } \\
\text { support might occur through local Indigenous teaching assistants. } \\
\text { Their L1 may or may not be recognised or valued in the school, may } \\
\text { or may not have a standardised spelling system or literacy resources. }\end{array}$ \\
- L1 speaking staffing
\end{tabular}

The diversity and complexity of Indigenous EAL/D learning contexts requires expanded conceptualisations of EAL/D teaching and assessment responses. Therefore, in parallel with this recent research on Indigenous languages and their educational implications, pedagogical and assessment initiatives have helped respond to Indigenous $\mathrm{EAL} / \mathrm{D}$, and we turn to these now. 


\section{Centring teaching of EAL/D (ESL/EFL) Indigenous learners in whole class, mainstream curriculum settings}

Two major research initiatives funded by the commonwealth Department of Education, Employment and Workplace Relations (DEEWR) have provided a strong research basis about building educators' capacity to support Indigenous EAL/D learners in mainstream whole class contexts.

Firstly, the Understanding Children's Language Acquisition Project (UCLAP) (see Angelo, 2009) took place over two years from 2007-9. It is noteworthy for its still pioneering exploration of young Indigenous (3.5 - 4.5 years) EAL/D learners in linguistically rich and complex situations in over 70 regional and remote Early Childhood Education (ECE) settings. It generated 3-way strong, a strength-based model of multilingualism for teachers of young Indigenous children, acknowledging how traditional languages, newer contact languages and EAL/D might all contribute to their language repertoires. Through collaborative participatory research, the project conducted interviews with Indigenous educators about their personal experiences and observations of languages in education and video recorded interactions of young Indigenous children in their ECE settings across mainland Queensland and the Torres Strait. This research flowed into frameworks for professional development of ECE educators, building their language awareness and providing processes for observing young learners' language use. The project helped establish the extent to which young learners were speakers of Indigenous languages, traditional and new, which were not mutually comprehensible with Standard Australian English and the pivotal role in ECE settings of local Indigenous staff with the same language repertoires as the children.

Secondly came the 2011-2013 Bridging the Language Gap (BLG) project (DETE (Qld), 2013) which involved 86 state and Catholic sector schools. This state-wide project built capacity for teaching Indigenous EAL/D learners in whole class, mainstream curriculum contexts. The project took place against the backdrop of NAPLAN-induced literacy interventions which often marginalise EAL/D responses for Indigenous students, even in English as a Foreign Language learning contexts. The BLG built EAL/D teaching capacity through iterative, wrap around training and 
mentoring for school nominated Language Leaders and teacher colleagues. Extensive Language Leaders workshops and follow up mentoring developed awareness of Indigenous student language backgrounds along with an EAL/D knowledge base around L2 acquisition, EAL/D planning, teaching and assessment, as well as leadership skills. Their teacher colleagues received "entry level" EAL/D workshops so they could work effectively with their school Language Leader. The project implemented frameworks for developing in-depth language awareness (the Language Awareness Continuum), promoting multilingualism (3-way Strong) and differentiating planning for teaching EAL/D (EFL/ESL) through content and language integrated learning (CLIL) (the Break it down, Build it up framework).

These frameworks contain conceptualisations for recognising and working with Indigenous EAL/D learners' language backgrounds and for planning, teaching and assessing in whole class, mainstream curriculum settings. They are presented here for the TESOL field as illustrations of important pedagogical responses along with their rationale, to enable their inclusion in future TESOL advocacy and toolkits.

\subsection{Language Awareness Continuum framework}

For speakers of creoles and Indigenised English varieties, language awareness is an integral part of a recognition process, with the added layer of critical language awareness (Fairclough, 1992; Wallace, 1999; Siegel, 2010) addressing their minoritised positioning compared to standard national languages. The Language Awareness Continuum (Angelo, 2006) is specifically designed for recognising new Indigenous contact languages with school-aged students and their teachers for pedagogical classroom purposes (see Figure 3). The hierarchy of concepts guides learning and frames discussions, so students, teachers and community members can probe a local contact language ecology together, and increasingly deeply, over time (see Carter et al., 2020, Appendix 1 for a sample suite of language awareness activities). 
Figure 3. Language Awareness Continuum-The conceptual hierarchy

\begin{tabular}{|c|} 
Which languages are spoken and why? \\
How are these languages structured? \\
$\begin{array}{c}\text { Explain linguistic, historical and current relationship between contact } \\
\text { and other non-standard varieties to standard languages }\end{array}$ \\
$\begin{array}{l}\text { Study historical \& present socio-economic factors in language shift } \\
\text { Contrast different languages' ways of fulfilling same functions }\end{array}$ \\
$\begin{array}{l}\text { Research history of language use in the community } \\
\text { Analyse features of languages spoken by students and community }\end{array}$ \\
\hline $\begin{array}{l}\text { Investigate language varieties spoken in the wider community } \\
\text { Compare 'home language' and 'standard English' at all linguistic levels }\end{array}$ \\
\hline $\begin{array}{l}\text { Identify factors involved in making language choices } \\
\text { Differentiate 'home language' from 'standard English' using language features }\end{array}$ \\
\hline $\begin{array}{l}\text { Negotiate names for the different kinds of language in students' lives } \\
\text { Recognise obvious markers of linguistic differences in language use in the classroom }\end{array}$ \\
\hline Notice different kinds of talk used by familiar people in everyday contexts
\end{tabular}

Note. Angelo (2006)

Table 2 below illustrates how implementing the Language Awareness Continuum (e.g. Carter et al., 2020, pp. 160-182) has innovated on language awareness programs for contemporary Indigenous contact language ecologies. The elements of "accommodation" of first languages/dialects, "sociolinguistic study" and "contrastive analysis" are included, which is typical of most such programs. However, the "critical positioning" of the various languages in students' milieu is also explicitly addressed, as this has been shown to achieve greater educational impact (Siegel, 2010). Additionally, concepts about language awareness are developed with increasing depth and scope in developmental stages (hierarchy of "concept development"), in order to rectify systemic invisibility of new Indigenous contact languages and their ecologies in school settings. This indicates that "(critical) language awareness" is not achieved in a one-off lesson, but is deep knowledge built with engagement with successively more sophisticated concepts. This fosters recognition of students' L1/ D1 and hence of their potential EAL/D learning needs. "Second language/dialect teaching" prevents linguistic submersion in Standard Australian English. Finally, language asymmetries between teachers and students require that language awareness is 
a "reciprocal learning" endeavour built on solid respectful relationships through "community engagement".

\section{Table 2. Components of Language Awareness}

\begin{tabular}{|c|c|c|}
\hline Source & Component & Purpose \\
\hline \multirow{3}{*}{$\begin{array}{l}\text { typically addressed } \\
\text { in language } \\
\text { awareness } \\
\text { programs }\end{array}$} & accommodation & $\begin{array}{l}\text { accepting and respecting Indigenous students' new } \\
\text { (contact) languages or ethnolects in educational } \\
\text { settings }\end{array}$ \\
\hline & sociolinguistic study & $\begin{array}{l}\text { learning that there are different language varieties, } \\
\text { and about who speaks which kind when and to } \\
\text { whom }\end{array}$ \\
\hline & contrastive analysis & $\begin{array}{l}\text { comparing the features of new (contact) languages } \\
\text { and/or ethnolects with a standardised national } \\
\text { language }\end{array}$ \\
\hline $\begin{array}{l}\text { greater impact } \\
\text { (Siegel 2010) }\end{array}$ & critical positioning & $\begin{array}{l}\text { understanding the socio-political dimensions of how } \\
\text { different languages/varieties are valued and } \\
\text { positioned }\end{array}$ \\
\hline \multirow{4}{*}{$\begin{array}{l}\text { additional } \\
\text { components for } \\
\text { school settings } \\
\text { (e.g. Angelo \& } \\
\text { Carter, } 2015 ; \\
\text { Angelo et al., } \\
\text { 2019; Carter et al., } \\
\text { 2020) }\end{array}$} & concept development & $\begin{array}{l}\text { building language awareness curricula with } \\
\text { concepts of increasing depth and scope }\end{array}$ \\
\hline & $\begin{array}{l}\text { part of second } \\
\text { language/ dialect } \\
\text { (L2/D2) teaching }\end{array}$ & $\begin{array}{l}\text { recognising Indigenous students' new Indigenous } \\
\text { contact language/ethnolect enables necessary } \\
\text { language-based support for learning national } \\
\text { language }\end{array}$ \\
\hline & reciprocal learning & $\begin{array}{l}\text { working with both teachers' and students' } \\
\text { knowledge and beliefs about each other's languages }\end{array}$ \\
\hline & $\begin{array}{l}\text { community } \\
\text { engagement }\end{array}$ & $\begin{array}{l}\text { involving wider Indigenous community in language } \\
\text { awareness discussions and resource development }\end{array}$ \\
\hline
\end{tabular}

Note. Adapted and updated from Angelo \& Carter, 2015, pp. 126-129

\subsection{3-way Strong framework}

Given Australia's infamous "monolingual mindset" (Clyne, 2005), it is unsurprising that "multilingualism" is a concept not automatically nor easily embraced by schools. In contact language ecologies, multilingualism can be even more difficult to conceptualise and celebrate as these languages may only be slowly gaining recognition and acceptance through a language awareness process. To assist schools and teachers negotiate a positive appreciation for their Indigenous students' language repertoires, the 3-way Strong model was developed.

As the name clearly states, this is a strengths-based approach. "3-way" refers to the characteristic make-up of rich and complex Indigenous language contexts where traditional/heritage languages, English-lexified contact varieties and Standard 
Australian English all exist. It is a reminder that the educational aim is additive multilingualism. As well as highlighting these three kinds of language, the 3-way Strong model indicates the differential role educators play in supporting each. This model has been used in state-wide education policy (DETE (Qld), 2011[2018], pp. 5-6) and feeds into the Indigenous language ecology work of contemporary national policy (Angelo et al., 2019; DoITRDC et al., 2020), and would be a welcome perspective in future TESOL advocacy around L1 support.

Figure 4. 3-way Strong: Placing traditional, contact and standard languages in schools

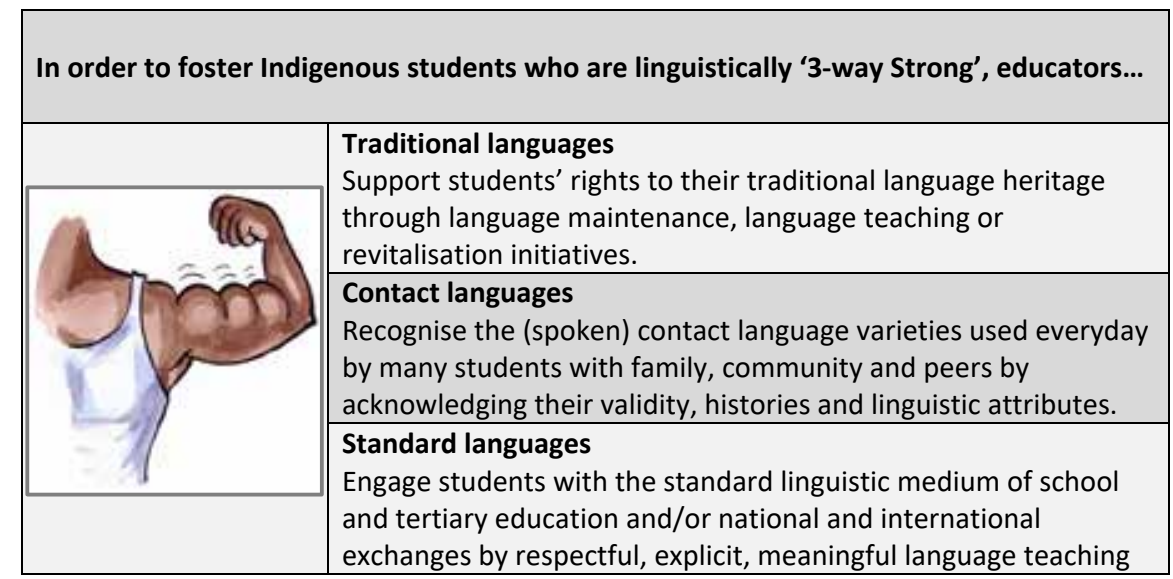

Note. Compiled from Angelo, 2009, pp. 5-6

\subsection{Break It Down, Build It Up Framework supporting whole class teaching of EAL/D across the curriculum}

Language awareness and multilingual frameworks pave the way for EAL/D teaching responses. They provide the reason, namely the recognition that students speak L1 varieties other than Standard Australian English. In the BLG, a formalised EAL/D teaching and learning framework was implemented, suitable for non-specialist educators, teaching whole classes, with a range of EAL/D learner proficiencies, including intensive language support needs. This planning framework, Break it Down Build it Up (DET 2020, pp. 129-130) fosters EAL/D teaching across mainstream curriculum areas, so, perforce, broadly follows what is nowadays 
commonly known as a content and language integrated learning (CLIL) approach (Coyle et al., 2010).

The Break it Down, Build it Up framework models "breaking down" (analysing) the English language demands of mainstream tasks in comparison to evidence of students' current outputs, and then "building up" (explicitly teaching) target language structures and features necessary for students to engage with and meet the content learning and language and literacy demands of tasks. The building up process encourages the use of a rich foundational text as a base, and a spiral curriculum approach moving from meaning making via oral language based activities, to literacy activities, to in-depth curriculum area learning, which all feeds into final assessment tasks.

TESOL professionals will see that this is similar to and overlaps with classical TESOL methodology. Yet engagement with the Standard Australian English language system needs to be at considerable depth. Many Indigenous EAL/D learners require intensive language support to access the mainstream curriculum content. This need is due to the compounding of factors such as EFL settings, lexical overlap between first and second languages, inconsistent provision of EAL/D-informed pedagogies and plateauing with less than advanced levels of EAL/D proficiency. For this cohort, it is insufficient to employ "post-intensive" methods of unpacking the task according to the curriculum, cultural etc load and teaching the structure and key features of the assessment genre. Nor has an emphasis on academic language, alone, been found to be sufficient. In contrast, the CLIL-aligned framework of Break it Down Build it Up encourages teachers of mainstream curriculum to EAL/D learners to foreground the English language demands of assessment tasks. They compare these with evidence of what students already command and hence identify, up front, language elements they will need to teach, not just the genre-based features. Key here is the focus on teaching language demonstrably required by learners (front-ended in planning, plus drawn from needs demonstrated in teaching and learning interactions) while teaching mainstream curriculum area content. 
Figure 5. Break it Down Build it Up Framework

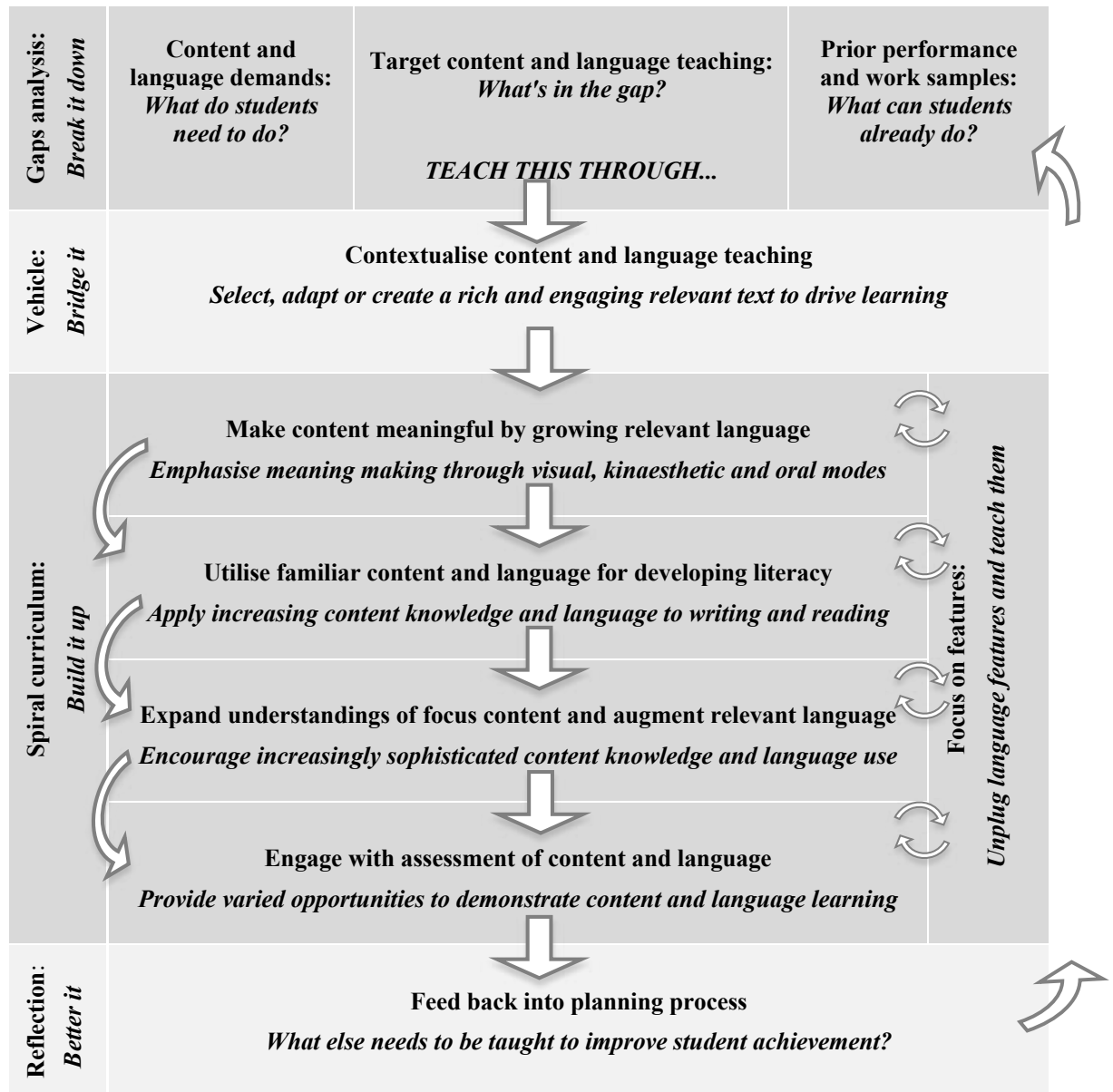

Note. From Angelo \& Carter, 2015, p. 135

\section{Centring the EAL/D Assessment of EAL/D (ESL/EFL) Indigenous learners in whole class, mainstream curriculum settings}

Identification is the first step to EAL/D learners having the right to differentiated teaching, quite outside matters of eligibility to targeted funding. There is a huge weight of evidence that standard questions on school enrolment forms do not elicit L1s or EAL/D status for many Indigenous students. The additional questionnaires and surveys that are part of TESOL professionals' toolkits cannot be utilised because most of their underpinning assumptions do not apply. Consequently, different identification processes and assessment tools tailored for Indigenous EAL/D learners' contexts have been developed and these are now described. 


\subsection{An inclusive identification process: Post-enrolment, classroom-assessed pathway}

If we take Queensland state schools as an example, we find that nowadays it is a requirement on teachers to identify, assess and monitor all EAL/D learners using the Bandscales State Schools (EQ, $2008 \mathrm{a})^{\mathrm{v}}$ and to provide language support according to proficiency need, including pedagogical differentiation (see current DoE (Qld), 2019). In order to encompass the full EAL/D cohort, inclusive of Indigenous EAL/D learners with invisible language backgrounds, statewide documents have had a classroom pathway of identification added to the on-enrolment pathway for over a decade (e.g. EQ, 2008b; DoE (Qld), 2017). The on-enrolment pathway typical in TESOL circles is especially suited to EAL/D learners newly arriving in the country, but it leads to underrecognition of Indigenous EAL/D learners (see Angelo, 2013, and in the US, Carjuzaa \& Ruff, 2016). This inequity is addressed by the clearly articulated, extra classroom identification pathway. This aims to put to rights any exclusionary practices relying solely on processes suited to migrant/refugee EAL/D learners based on country of origin, visa and time of arrival, overseas languages etc. which do not apply to Indigenous populations (for similar issues in the US see Linquanti \& Bailey, 2014).

\subsection{Responding to local contexts by expanding concepts for EAL/D assessment}

Historically, both the first national L2 proficiency assessment tools developed for schools, the NLLIA Bandscales (McKay et al., 1994) and the ESL Scales (AEC, 1994), did not explicitly include Indigenous EAL/D learners and their specific contexts. Although the recent ACARA $(2011 / 2014,2015) \mathrm{EAL} / \mathrm{D}$ materials have taken welcome steps in this direction, they lack the rationale, the extensive conceptual underpinnings of materials in jurisdictions where the Indigenous EAL/D cohort is considerable or even dominates. In these jurisdictions, systems have developed assessment tools by engaging deeply with Indigenous EAL/D learner trajectories.

If we take the Bandscales State Schools as an example, it responds to the need for an EAL/D assessment framework for the full cohort of EAL/D learners, which is also sensitive to the language and learning contexts of Indigenous learners. The Bandscales State Schools, a summary EAL/D proficiency scale for generalist classroom teachers, is a daughter scale of the NLLIA 
ESL Bandscales (McKay et al., 1994) and draws heavily on its adaptation Bandscales for Aboriginal and Torres Strait Islander Learners (EQ, 1999/2002). Extra underpinning concepts were required to include the Indigenous EAL/D cohort's language situations and language learning trajectories and to focus on mainstream teachers' use. Their theoretical and teacher practice research base is detailed in Hudson and Angelo (2014).

The Bandscales State Schools expand on the contextual nature of the original NLLIA Bandscales (see McKay 2000, 2007) to flag the language and learning situations of Indigenous students, particularly speakers of new Indigenous contact language varieties. They not only mark the critical role of mainstream teachers in identifying invisible EAL/D learners (e.g. contact language speakers), but contain messages for teachers, NLLIA Bandscales style, of the implications of mistaking apparent communicative ability as proficiency in SAE, leading to plateauing at early stages of L2 development (Angelo \& Hudson, 2018; Hudson \& Angelo, 2020). The contextual descriptors in the Bandscales State Schools also link proficiency levels with responding levels of teacher support, following the original NLLIA contextual descriptors and expanding on them, contrasting with the de-contextualised outcomes-based descriptors in scales following the ESL Scales model (McKay, 2000; Moore, 1995). Contextualised descriptors incorporating teacher support are useful for guiding generalist teachers in mainstream curriculum contexts about the teaching and learning implications of different levels of proficiency. For example, that a student at a post-beginner level of proficiency is reliant on high contextualisation and intensive language teaching support to operate at that level. Best teaching responses are encouraged by descriptors which link proficiency levels to teacher language support, rather than decontextualized descriptors which can suggest that proficiency development is focussed on the child alone (see Hudson \& Angelo, 2014).

The Bandscales State Schools also adopt the finer grained extra early levels developed in the Bandscales for Aboriginal and Torres Strait Islander Learners to account for extended pathways for students from oral language traditions with little or no experience of L1 print literacy, and, frequently, the need to develop language awareness to assist with the complicated process of disentangling the L2 target. These levels also make room for those in remote EFL contexts where students and community members speak a 
language other than English for all everyday interactions, different to ESL immersion L2 learning contexts common in other parts of Australia.

\section{Conclusion}

This paper lays out why the Australian TESOL profession can and should make a concerted effort to put the interests of First Nations EAL/D learners at the heart of future policy and advocacy initiatives. Australian TESOL specialists have a tradition of recognising diversity within the EAL/D cohort and becoming informed in order to support social justice and educational outcomes. Although increasingly inclusive of Indigenous EAL/D learners, it has nevertheless been shown here that this recognition and support has been unreliable, tending to forgettings and by nature somewhat cursory, despite best intentions. As we explain, this is understandable given inherited funding settings, because TESOL services - and hence research, teaching and assessment expertise - have been focussed predominantly on EAL/D learners with overseas backgrounds.

We therefore argue here for a greater engagement with the concepts and issues of significance for Aboriginal and Torres Strat Islander EAL/D learners. For such reasons, this paper describes concepts and practices that respond to the diversity of Indigenous EAL/D learners, including those from un-/under-described language contact situations, and their English language learning contexts. The hope is that this will address past history by assisting in bringing the Indigenous EAL/D cohort to the centre of TESOL discourse and initiatives.

\section{References}

Angelo, D. (2006). Language Awareness Continuum [Unpublished teacher resource]. Cairns: Language Perspectives, Far North Queensland Indigenous Schooling Support Unit.

Angelo, D. (2009). Understanding Children's Language Acquisition Project [Web-based Report based on the Final Report for the Strong Indigenous Communities and English Acquisition Project]. Available from https://web.archive.org/ web/20130502094148/http://languageperspectives.org.au/

Angelo, D. (2012). Sad stories. A preliminary study of NAPLAN practice texts analysing students' second language linguistic resources and the effects of these on their written narratives. 
In M. Ponsonnet, L. Dao, \& M. Bowler (Eds.), Proceedings of the 42nd Australian Linguistics Society conference - 2011. Retrieved from http://hdl.handle.net/1885/9313.

Angelo, D. (2013). Identification and assessment contexts of Aboriginal and Torres Strait Islander learners of Standard Australian English: Challenges for the language testing community. Papers in Language Testing and Assessment, 2(2), 67-102.

Angelo, D. (2021). Creoles, education and policy. In U. Ansaldo \& M. Meyerhoff (Eds), The Routledge Handbook of Pidgin and Creole languages (pp. 286-301). Abingdon UK/New York: Routledge.

Angelo, D. (in press a). Case studies from Australia's shifting langscapes . In C. Bowern (Ed.), Handbook of Australian Languages, Oxford: Oxford University Press.

Angelo, D. (in press b). Language contact and contact languages. In C. Bowern (Ed.), Handbook of Australian Languages, Oxford: Oxford University Press.

Angelo, D., \& Carter, N. (2015). Schooling within shifting langscapes: Educational responses within complex Indigenous language ecologies. In A. Yiakoumetti (Ed.), Multilingualism and Language in Education: Current Sociolinguistic and Pedagogical Perspectives from Commonwealth Countries (pp. 119-140). Cambridge: Cambridge University Press.

Angelo, D., Fraser, H., \& Yeatman, B. (2019). The art of recognition. Visualising contact languages with community vernacular language posters. Babel, 54(1-2), 34-40.

Angelo, D., \& Hudson, C. (2018). Dangerous conversations: Teacher-student interactions with unidentified English language learners. In G. Wigglesworth, J. Simpson, \& J. Vaughan (Eds.), Language practices of Indigenous youth (pp. 207-235). London: Palgrave Macmillan.

Angelo, D., \& McIntosh, S. (2014). Anomalous data about Aboriginal and Torres Strait Islander language ecologies. In E. Stracke (Ed.), Intersections: Applied Linguistics as a Meeting Place (pp. 270-293). Newcastle upon Tyne: Cambridge Scholars Publishing.

Angelo, D., O'Shannessy, C., Simpson, J., Kral, I., Smith, H., \& Browne, E. (2019). Well-being E् Indigenous language ecologies 
(WILE): A strengths-based approach. Literature Review for the National Indigenous Languages Report, Pillar 2. Canberra: The Australian National University, http://hdl.handle. net/1885/186414.

Australian Curriculum, Assessment and Reporting Authority (ACARA). (2011/2014). English as an additional language/ dialect: A teacher resource. Overview and advice, https://docs. acara.edu.au/resources/EALD_Overview_and_Advice_ revised_February_2014.pdf

Australian Curriculum, Assessment and Reporting Authority (ACARA). (2011/2015). English as an additional language/ dialect: A teacher resource. EAL/D progression: Foundation to Year 10, https://docs.acara.edu.au/resources/EALD_ Learning_Progression.pdf

Australian Curriculum, Assessment and Reporting Authority (ACARA). (n.d.). Student Diversity Resources: Meeting the needs of students for whom English is an additional language or dialect. Retrieved from https://www.australiancurriculum. edu.au/resources/student-diversity/meeting-the-needs-ofstudents-for-whom-english-is-an-additional-language-ordialect/

Australian Council of TESOL Associations (ACTA). (2019). Submission to the Productivity Commission September Draft Report National Education Evidence Base [Submission DR120], https://www.pc.gov.au /__data/assets/pdf_ file/0004/208903/subdr120-education-evidence.pdf

Australian Education Council (AEC) (1994). The ESL Scales. Carlton, VIC: Curriculum Corporation.

Carjuzaa, J., \& Ruff, W. G. (2016). American Indian English Language Learners: Misunderstood and under-served. Cogent Education, 3, 1-11.

Carter, N., Angelo, D., \& Hudson, C. (2020). Translanguaging the curriculum: A critical language awareness curriculum for silenced Indigenous voices,. In P. Mickan \& I. Wallace (Eds.), Language Education Curriculum Design (pp. 144-174). New York/London: Routledge Taylor and Francis.

Centre for Education Statistics and Evaluation (CESE). (2013). Assessing English language proficiency. Learning Curve, 4. Sydney: NSW Department of Education and Communities, https://www.cese.nsw.gov.au/publications-filter/assessingenglish-language-proficiency 
Centre for Education Statistics and Evaluation (CESE). (2015). $N S W$ trial of the reliability and validity of the EAL/D (English as an Additional Language/Dialect) Learning Progression. Sydney: NSW Department of Education and Communities, https:/ www.cese.nsw.gov.au/images/stories/PDF/English_as_an_ additional_language_learning_progression_Oct15.pdf

Clyne, M. (2005). Australia's Language Potential. Sydney: University of New South Wales Press.

Coyle, D., Hood, P., \& Marsh, D. (2010). Content and language integrated learning. Cambridge: Cambridge University Press.

Creagh, S. (2014). NAPLaN test data, ESL Bandscales and the validity of EAL/D teacher judgement of student performance. TESOL in Context, 24(2), 30-50.

Cummins, J. (1984). Bilingual Education and Social Education: Issues in Assessment and Pedagogy, College Hill, San Diego.

Davison, C., \& Michell, M. (2014). EAL assessment: What do Australian teachers want? TESOL in Context, 24(2), 51-72.

Department of Education (DoE) (Qld). (2017), Identifying Aboriginal and Torres Strait Islander 'English as an additional language or dialect (EAL/D)' students, https://education.qld.gov.au/ student/Documents/identifying-aboriginal-torres-straitislander-eald-learners-flowchart.pdf

Department of Education (DoE) (Qld). (2019). P-12 curriculum, assessment and reporting framework, https://education.qld. gov.au/curriculums/Documents/p12-carf-framework.pdf.

Department of Education, Science \& Technology (DEST). 2004. Indigenous education programmes. Provider guidelines 2005 2008 [Part A], Canberra: Australian Government. Retrieved from https://www.aph.gov.au/ /media/Estimates/Live/ eet_ctte/estimates/add_0405/dest/part_a.ashx

Department of Education \& Training (DET) (Qld). (2020). Teaching Aboriginal and Torres Strait Islander English as an Additional Language or Dialect (EAL/D) learners. A national review of programs and approaches. Brisbane: State of Queensland (DET).

Department of Education Training \& Employment (DETE) (Qld). (2011). Aboriginal and Torres Strait Islander languages statement [Revised 2018]. Brisbane: State of Queensland, https:// education.qld.gov.au/student/Documents/aboriginaltorres-strait-islander-languages-statement.pdf. 
Department of Education, Training \& Employment (DETE) (Qld). (2013). Bridging the Language Gap [Unpublished (Evaluation) Report]. Brisbane: State of Queensland.

Department of Infrastructure, Transport, Regional Development and Communications (DoITRDC), Australian Institute for Aboriginal and Torres Strait Islander Studies (AIATSIS) and Australian National University (ANU). (2020). National Indigenous Languages Report. Canberra: Australian Government. Retrieved from https://www.arts.gov.au/ what-we-do/indigenous-arts-and-languages/nationalindigenous-languages-report.

Devlin, B., Disbray, S., \& Friedman Devlin, N. (Eds.). (2017). History of bilingual education in the Northern Territory: People, programs and policies. Singapore: Springer Publishing.

Dickson, G. (2019). Aboriginal English(es). In L. Willoughby \& H. Manns (Eds.), Australian English reimagined: Structure, features and developments (pp. 134-153). Oxon: Routledge.

Disbray, S., \& Simpson, J. (2004). The expression of possession in Wumpurrarni English, Tennant Creek. Monash University Linguistics Papers, 4(2), 65-86.

Dixon, S. (2018). Alyawarr children's use of two closely related languages. In G. Wigglesworth, J. Simpson, \& J. Vaughan (Eds.), Language practices of Indigenous children and youth (pp. 271-299). London: Palgrave Macmillan.

Dixon, S., \& Angelo, D. (2014). Dodgy data, invisibility and the implications for social inclusion. A critical analysis of Indigenous student language data in Queensland schools. Australian Review of Applied Linguistics, 37(3), 213-233.

Eades, D. (2014). Aboriginal English. In H. Koch \& R. Nordlinger (Eds.), The languages and linguistics of Australia. A comprehensive guide (pp. 417-447). Berlin/Boston: de Gruter Mouton.

Education Queensland (EQ). (1999/2002). Bandscales for Aboriginal and Torres Strait Islander learners. Retrieved from https:// web.archive.org/web/20171026142838/http://education. qld.gov.au/students/evaluation/monitoring/bandscales/ index.html.

Education Queensland (EQ). (2008a). EQ Bandscales for English as a Second Language/Dialect (ESL/D) Learners, https:// education.qld.gov.au/student/Documents/bandscales-stateschools-qld.pdf. 
Education Queensland. (2008b). Curriculum guidelines for English as a Second Language (ESL) learners. Brisbane: State of Queensland.

Fairclough, N. (1992). Critical Language Awareness. London: Longman.

Fraser, H., Mushin, I., Meakins, F., \& Gardner, R. (2018). Dis, that and da other: Variation in Aboriginal children's article and demonstrative use at school. In G. Wigglesworth, J. Simpson, \& J. Vaughan (Eds.), Language practices of Indigenous children and youth (pp. 237-269). London: Palgrave MacMillan.

Gawne, L., Wigglesworth, G., Morales, G., Poetsch, S., \& Dixon, S. (2016). Making the ESL classroom visible: Indigenous Australian children's early education. In V. Murphy \& M. Evangelou (Eds.), Early Childhood Education in English for Speakers of Other Languages (pp. 111-136). London: British Council.

Gourlay, C., \& Mushin, I. (2015). 'Up dere la': Final particle la in a Queensland Aboriginal vernacular. Australian Journal of Linguistics, 34, 76-101.

House of Representatives Standing Committee on Aboriginal and Torres Strait Islander Affairs (HoRSCATSIA). (1992). Language and culture: a matter of survival. Report of the inquiry into Aboriginal and Torres Strait Islander language maintenance June 1992. Parliamentary Paper Number 164/1992. Canberra: Australian Government Publishing Service.

Hudson, C., \& Angelo, D. (2014). Concepts underpinning innovations to second language proficiency scales inclusive of Aboriginal and Torres Strait Islander learners: a dynamic process in progress. Papers in Language Testing and Assessment, $3(1), 44-84$.

Hudson, C. \& Angelo, D. (2020). Teacher views on the implementation of English language proficiency scales for young Indigenous learners of standard English. Language Assessment Quarterly, 17(5), 491-518.

Language Perspectives. (2009). At da crick: Yarrabah [Community Vernacular Language Poster], Cairns: Indigenous Schooling Support Unit, Department of Education and Training (Qld).

Linquanti, R., \& Bailey, A. L. (2014). Reprising the Home Language Survey: Summary of a National Working Session on Policies, 
Practices, and Tools for Identifying Potential English Learners. Council of Chief State Officers, https://files.eric.ed.gov/ fulltext/ED565756.pdf.

Lo Bianco, J. (1987). National Policy on Languages. Canberra: Australian Government Publishing Service.

Macqueen, S., Knoch, U., Wigglesworth, G., Nordlinger, R., Singer, R., McNamara, T., \& Brickle, R. (2019). The impact of national standardized literacy and numeracy testing on children and teaching staff in remote Australian Indigenous communities. Language Testing, 36(2), 265-287.

Malcolm, I. (2002). Aboriginal English Genres in Perth. Mt Lawley, WA: Edith Cowan University.

Malcolm, I. (2018). Australian Aboriginal English. Change and continuity in an adopted language. Berlin: de Gruyter Mouton.

McKay, P. (2000). On ESL standards for school-age learners. Language Testing, 17(2), 185-214.

McKay P. (2007). The Standards Movement and ELT for SchoolAged Learners. In J. Cummins \& C. Davison C. (Eds), International Handbook of English Language Teaching (pp. 439-456). Boston, MA: Springer.

McKay, P., Hudson, C., \& Sapuppo, M. (1994). ESL Bandscales. In NLLIA ESL development: Language and literacy in schools project (Vol 1, pp. B1-D52). Canberra: National Languages and Literacy Institute of Australia (NLLIA).

McTaggart, R. \& Curro, G. (2009). Book language as a foreign language: ESL strategies for Indigenous learners. Report of research commissioned by the Queensland College of Teachers. Toowong: Queensland College of Teachers, https:// researchonline.jcu.edu.au/5572/2/5572_McTaggart_and_ Curro_2009.pdf

Meakins, F. (2013). Gurindji Kriol. In S. M. Michaelis, P. Maurer, M. Haspelmath, \& M. Huber (Eds.), The survey of pidgin and creole languages (Vol. III, pp. 131-140). Oxford: Oxford University Press.

Mittag, J. (2016). A linguistic description of Lockhart River Creole. (PhD thesis, University of New England, Armidale NSW), https://rune.une.edu.au/web/bitstream/1959.11/22591 /5/open/SOURCE03.pdf

Moore, H. (1995) Telling the history of the 1991 Australian Language and Literacy Policy. TESOL in Context, 5(1), 6-20. 
Munro, J., \& Mushin, I. (2016). Rethinking Australian Aboriginal English-based speech varieties: Evidence from Woorabinda. Journal of Pidgin and Creole Languages, 31(1), 82-112.

Mushin, I., Angelo, D., \& Munro, J. (2016). Same but different: Understanding language contact in Queensland Indigenous Settlements. In J-C. Verstraete and D. Haffner (Eds.), Land and language in Cape York and the Gulf country. Festschrift for Bruce Rigsby. Culture and Language Use 18 (pp. 383-408). Amsterdam: John Benjamins Publishing Company.

Mushin, I., Gardner, R., \& Munro, J. M. (2013). Language matters in demonstrations of understanding in early years mathematics assessment Mathematics Education Research Journal (MERJ), 25(3), 415-433.

Mushin, I., \& Watts, J. (2016). Identifying the grammars of Queensland ex-government Reserve varieties: The case of Woorie Talk. In F. Meakins \& C. O'Shanessy (Eds.), Loss and renewal. Australian languages since colonisation (pp. 57-85). Berlin: Mouton de Gruyter.

Nancarrow, C. (Ed.) (2014). Seagull and crane : a traditional Lardil story (Illustrated by year 4 students at Mornington Island State School, with Mornington Island Creole notes). Gununa, Qld: Mirndiyan Gununa Aboriginal Corporation.

Oliver, R., Rochecouste, J., \& Nguyen, B. (2017). ESL in Australia - A chequered history. TESOL in Context, 26(1), 7-26.

O'Shannessy, C. ( 2005). Light Warlpiri: A new language. Australian Journal of Linguistics, 25, 31-57.

Sellwood, J., \& Angelo, D. (2013). Everywhere and nowhere: Invisibility of Aboriginal and Torres Strait Islander contact languages in education and Indigenous language contexts. Australian Review of Applied Linguistics, 36(3), 250-266.

Siegel, J. (2010). Second Dialect Acquisition. Cambridge: Cambridge University Press.

Shnukal, A. (1988). Broken: an introduction to the creole language of Torres Strait. Canberra: Dept. of Linguistics, Research School of Pacific Studies, Australian National University.

Shnukal, A. (2001). Torres Strait English. In D. Blair \& P. Collins (Eds.), English in Australia (pp. 181-200). Amsterdam: John Benjamins.

Wallace, C. (1999). Critical language awareness: Key principles for a course in critical reading. Language Awareness, 8: 98-110. 


\section{Endnotes}

(i) The use of the term 'Indigenous' follows the usage in current international social justice documents, and is intended to be inclusive of both Aboriginal and Torres Strait populations. In terms of English language learners, it distinguishes the cohort who are not learning English because of an overseas language background.

(ii) Variants of the term 'English as an Additional Language (or Dialect) (EAL(/D))' are now current across Australian jurisdictions. This term subsumes all English language learning contexts such as English as a Foreign Language, as a Second/Other Language, as a Second Dialect etc.

(iii) This approach has had many permutations largely because of inconsistent identification, funding and reporting of the Indigenous EAL/D cohort in the different jurisdictions at different times, and may variably target different staff (e.g. local Indigenous staff, beginner teachers etc), specific Indigenous student cohorts (e.g. in remote schools, Aboriginal English speakers, dual language programs, raising awareness of speakers of contact languages etc). Likewise, delivery modes vary (face to face, online, in-class coaching, formal qualifications based etc) as does the makeup of the delivery team which typically includes one or more language specialists, perhaps TESOL professionals, local Indigenous language speakers, linguists, language teachers, upskilled experienced classroom teacher coaches etc.

(iv) For initiatives in other states up until 2014, readers are referred to the national overview of programs and approaches for Indigenous EAL/D learners (DET (Qld) 2020).

(v) The Bandscales State Schools (Qld), were originally entitled Bandscales for English as a Second Language/Dialect (ESL/D) Learners when first published in 2008.

Denise Angelo is a $\mathrm{PhD}$ student at ANU. She develops and researches education policy and services differentiated for Indigenous students from Indigenous languages ecologies, including traditional and new Indigenous languages and EAL/D.

denise.angelo@anu.edu.au

Catherine Hudson is an Honorary Lecturer at ANU. Her current research is on EAL/D assessment in schools, with special application to Indigenous students. She has been a co-writer of and/or consultant on a number of EAL/D proficiency scales. 